\title{
APPLICATION OF RESONANCE METHOD FOR EXAMINING OF PISTON RING TECHNICAL CONDITION
}

\author{
Aleksandrs Gasparjans ${ }^{1}$, Aleksandrs Terebkovs ${ }^{1}$, Anastasija Ziravecka ${ }^{2}$ \\ ${ }^{1}$ Latvian Maritime Academy, Latvia; ${ }^{2}$ Riga Technical University, Latvia \\ aleksandrs.gasparjans@latja.lv, sashater@bkc.lv, zhiravecka@eef.rtu.lv
}

\begin{abstract}
The article is devoted to the questions of technical operation of the internal combustion engines. Some questions of the technical diagnostics of the engine piston rings are considered. The authors propose a resonance method for the examination of the piston rings. The idea of the method is to cause oscillations in the ring at the frequency of its own mechanical resonance and at the multiple harmonics. The amplitude of the ring oscillations is measured in the gap by means of sensors according to two coordinates simultaneously. The frequency, phase and amplitude of the oscillations depend on the mechanical properties of the ring's material and its geometry. Micro-cracks, the areas with stresses, hardening defects, local overheating, loss of elasticity and other defects cause deviations of the frequency, phase and amplitude from the standard. One of the special features of the proposed method is registration of the frequency response of the piston ring oscillations simultaneously in two planes - radial (the plane of the ring) and in the direction of the axis. It allows to discover the defects (microcracks, thermal inhomogeneity, etc.) of the ring independently on their orientation along the assumed axes. This is a kind of non-destructive methods.
\end{abstract}

Keywords: diagnostics, oscillations, frequency, amplitude, resonance.

\section{Introduction}

The piston rings are one of the important parts of the cylinder-piston group of internal combustion engines (ICE). A piston ring operates under very severe conditions - high temperatures, in the environment of aggressive chemical gases, with significant alternating mechanical stresses. The ring experiences continuous flexural-torsional vibrations in the grooves of the piston. The purpose of the piston ring is to segregate the combustion chamber and the crankcase space. The oil is supplied to the combustion chamber under the condition of increased gaps, the gases leak from the combustion chamber into the crankcase. This results in a significant deterioration of the technical and economic parameters of the engine and reduction of its service life.

The paper suggests a method of present technical condition of the piston ring determination and analysing its frequency response plot (FRP) of its forced and self oscillations. The measurements are realized at the frequencies close to those of its own mechanical resonance and its harmonics. Thus, the piston ring plays a kind of tuning fork. Then the obtained FRP are compared with the reference plots.

A lot of fundamental literature is devoted to the theory of mechanical oscillations [1-4]. Analysis of the literature in the theory of cylindrical casings is presented in [5-7], in beams and plates in [8; 9], in cylindrical closed rings in $[10 ; 11]$. However, the mathematical modelling of the oscillations and the processes in the split metal rings on the examples of the piston rings are not considered fully enough. This paper considers these questions directly. The basic purpose of it is to research the means of obtaining, registration and processing of the experimental data with their further analysis.

A ring can oscillate within its own plane (along the radius) as well as in the perpendicular direction - along own axis. In its first assumption the piston ring could be considered as a ring-form beam of a rectangular cross-section. A real piston ring has a more complex form. In the calculations the slit ring was assumed as inextensible, with a uniformly distributed mass and with a constant crosssection - Fig. 1.

In accordance with $[1 ; 2 ; 12]$ the oscillations in the plane of the ring (radial) can be described by means of equation (1):

$$
\frac{\partial^{6} X_{2}}{\partial \varphi^{6}}+2 \frac{\partial^{4} X_{2}}{\partial \varphi^{4}}+\frac{\partial^{2} X_{2}}{\partial \varphi^{2}}+\frac{m R^{4}}{E J} \frac{\partial^{2}}{\partial t^{2}}\left(\frac{\partial^{2} X_{2}}{\partial \varphi^{2}}-X_{2}\right)=0
$$

where $E J$ - rigidity of the cross-section during bending;

$E$ - elastic modulus, $\mathrm{Pa}$;

$J$ - moment of inertia of the cross-section regarding the central axis, $\mathrm{m}^{4}$; 


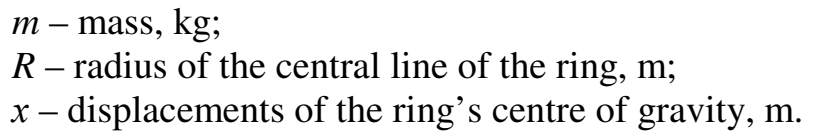

Reducing this equation to the differential type and solving it we will get the expression for calculation of the ring's radial $p_{k l}$ self-oscillations (along axis $X_{1}$, Fig. 1):

$$
p_{k 1}=\frac{k\left(k^{2}-1\right)}{\sqrt{k^{2}+1}} \sqrt{\frac{E J}{m R^{4}}},
$$

where $k$ - the factor called mode.

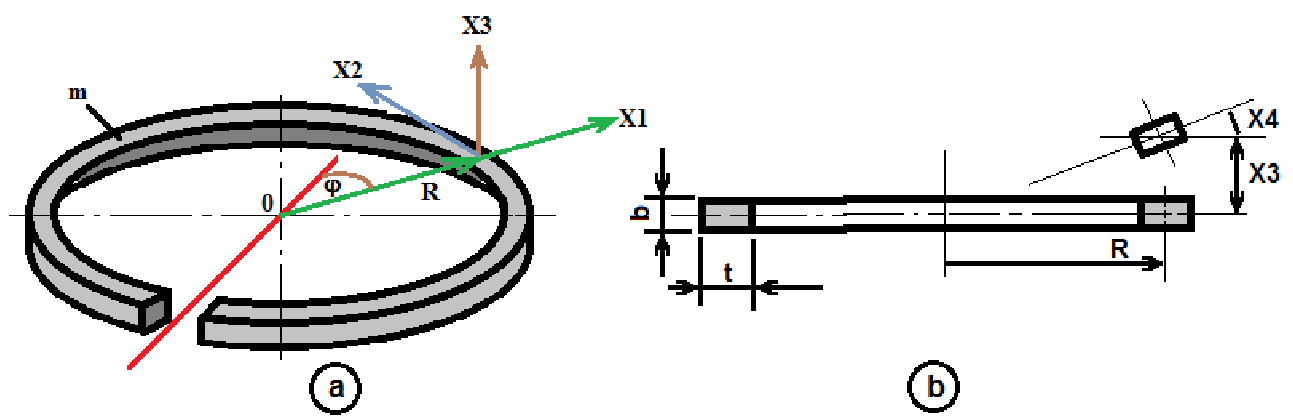

Fig. 1. Idealized model of a piston ring: $O$ - centre of gravity of the cross-section of the ring;

$R$ - radius of the ring; $X_{1}$ - radial displacement of the ring's centre of gravity; $X_{2}$ - tangential, circumferential displacement; $X_{3}$ - displacement perpendicular to the plane of the ring; $X_{4}-$ angle of the ring cross-section turning; $\varphi$ - angular coordinate of the centre of gravity

of the ring's cross-section

Value $k=1$ corresponds to the zero frequency. The forms of the oscillations of the ring at $k=1,2$, 3,4 are shown in Fig. 2 [1; 12; 13].

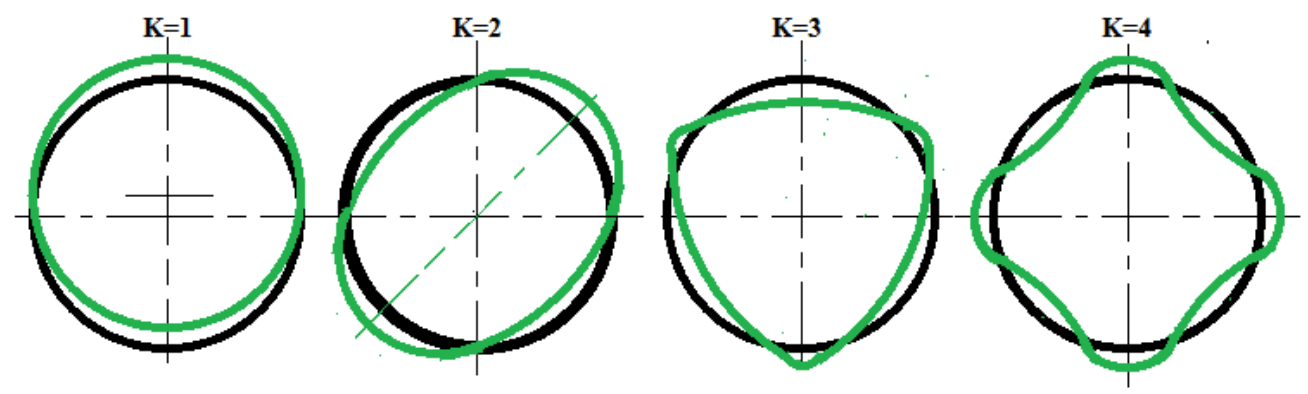

Fig. 2. Forms of the radial oscillations of the ring at different values of mode $k$

In accordance with $[1 ; 12]$ the oscillations in the axial plane (along axis $X_{3}$ ), perpendicular to the plane of the ring, could be described with (3):

$$
\frac{m R^{3}}{E J} \frac{\partial^{2} X_{3}}{\partial t^{2}}+\frac{\partial^{4} X_{3}}{R \partial \varphi^{4}}-\frac{G J_{k}}{E J_{1}} \frac{\partial^{2} X_{3}}{R \partial \varphi^{2}}+\left(1+\frac{G J_{k}}{E J_{1}}\right) \frac{\partial^{2} X_{4}}{\partial \varphi^{2}}=0
$$

then:

$$
\left(1+\frac{G J_{k}}{E J_{1}}\right) \frac{\partial^{2} X_{3}}{R \partial \varphi^{2}}-\left(\frac{G J_{k}}{E J_{1}} \frac{\partial^{2} X_{4}}{\partial \varphi^{2}}-X_{4}\right)=0,
$$

where $J_{1}-$ moment of inertia of the cross-section regarding to the central axis lying in the plane of the curvature;

$G J_{k}$ - torsional rigidity of the ring's cross-section.

The corresponding transformations result in the calculations of the self-oscillation relative frequencies $p_{k 2}$ of the ring in the axial direction (along axis $X_{3}$, Fig. 1): 


$$
p_{k 2}=\frac{k\left(k^{2}-1\right)}{\sqrt{k^{2} G J_{k} / E J_{1}+1}} \sqrt{\frac{G J_{k}}{m R^{4}}} .
$$

The minimum frequency different from zero is equal to $\mathrm{k}=2$. The above mentioned dependencies (1)...(5) are valid for the split ring as well [12].

\section{Materials and methods}

As indicated above the ring can oscillate along few axes $X_{1}-X_{4}$. Therefore, the obtaining of the frequency response plot of the piston ring requires minimum two sensors placed along the axes $X_{1}$ and $X_{3}$. Fig. 3 - sensors 4 and 5.

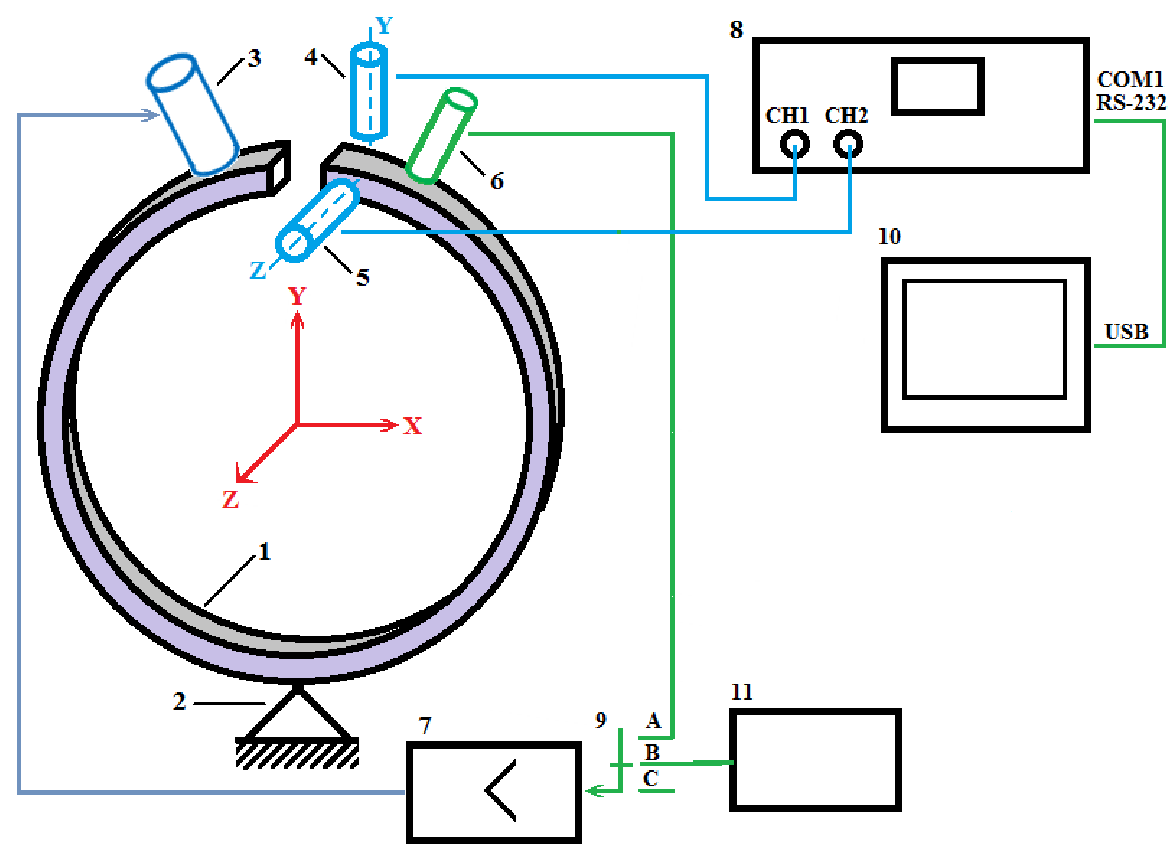

Fig. 3. Scheme of the board for the piston ring frequency response plot obtaining:

1 - piston ring; 2 - base; 3 - excitation electromagnet; 4 - magneto-electric sensor along axis $Y\left(X_{1}\right)$;

5 - magneto-electric sensor along axis $Z\left(X_{3}\right) ; 6$ - magneto-electric sensor of the amplifier 7;

7 - amplifier; 8 - digital oscilloscope; 9 - switch of the amplifier input: 10 - PC; 11 - sound generator

\section{Description of the scheme}

Fig. 3 demonstrates the scheme of the board for the obtaining of the frequency response plot of the piston ring. Piston ring 1 is rigidly fixed on the base 2 . The magneto-electric sensors recording the oscillations of the branches of the ring: sensor 4 records the radial oscillations of the ring; sensor 5- the axial oscillations perpendicular to the ring plane. Similar sensor 6 records the radial oscillations of the ring and transmits this signal to the amplifier of low frequency 7 by means of operation regimes of the switch 9. The output of this amplifier is connected with excitation electromagnet 3 . The signals from sensors 4 and 5 are supplied to the inputs $\mathrm{CH} 1$ and $\mathrm{CH} 2$ of the double channel oscilloscope 8 . The output of the digital oscilloscope 8 is connected to USB input of the computer 10.

\section{Operation of the board}

The oscillations of the piston ring are investigated in three regimes that are installed by means of the switch 9. In position "A" the signal from the sensor 6 is amplified by the amplifier of low frequency 7 . The amplified signal is supplied to excitation electromagnet 6 . In this case the scheme forms an auto generator with a positive feedback. In this case the piston ring operating like a tuning fork plays a role of frequency setting element. Then the system experiences undamped self-oscillations at the frequency of the main mechanical resonance of the piston ring. In position " $\mathrm{B}$ " the amplifier 7 is supplied with the signal of the sound generator 11 . The sound generator can provide the frequencies 
containing some multiple of the harmonics of the frequencies of the main mechanical resonance of the piston ring. It allows obtaining of additional information about the properties of the ring. In position "C" the low frequency amplifier 7 and excitation electromagnet 3 are not operating. This case gives an opportunity to investigate the oscillations of the ring in damping regime at the frequency of its own mechanical resonance. The initial oscillations are excited by means of a single mechanical hit by a steel ball on suspension. In all three regimes the sensors 4,5 , digital oscilloscope 8 and computer 10 are permanently operating. In this case the parameters of the oscillating process depend on the energy of hit as well. For its accurate determination the geometry of the ball and ring and the mechanical properties of their materials are required [14].

Calculation of the energy and time of the ball hit on the piston ring (Fig. 4). Let us assume that the ball is at the decline position. The length of the suspension is $l=0.8 \mathrm{~m}$; radius of the piston ring $R=0.251 \mathrm{~m}$; radius of the hitting ball $-r=0.011 \mathrm{~m}$; angle of the ball declination $-\alpha=10$ degrees; thickness of the ring $-0.0165 \mathrm{~m}$; mass of the ring $2.550 \mathrm{~kg}$; mass of the ball $-0.042 \mathrm{~kg} ; \mu_{1}=0.25-$ Poisson's ratio for the steel hitting ball; $\mu_{2}=0.3$ - Poisson's ratio for the piston ring (cast iron); $E=2 \cdot 10^{5} \mathrm{MPa}-$ elastic modulus.

The law of energy conservation for the hitting ball:

$$
m g h=\frac{m v^{2}}{2} .
$$

The height of the ball lifting d:

$$
\cos \alpha=\frac{d}{l}
$$

where from $d=1 \cos \alpha$.

Then

$$
2 g h=v^{2}, v=\sqrt{\frac{2 g h}{1}} .
$$

The duration of the ball hit $\tau$ onto the piston ring:

$$
\tau=2.9432\left(\frac{5 m}{4 k}\right)^{\frac{2}{5}} v^{-\frac{1}{5}} .
$$

where $m$-the mass of the hitting ball;

$v$ - speed of the ball at the instant of the hit;

$k$ - factor calculated with the formula.

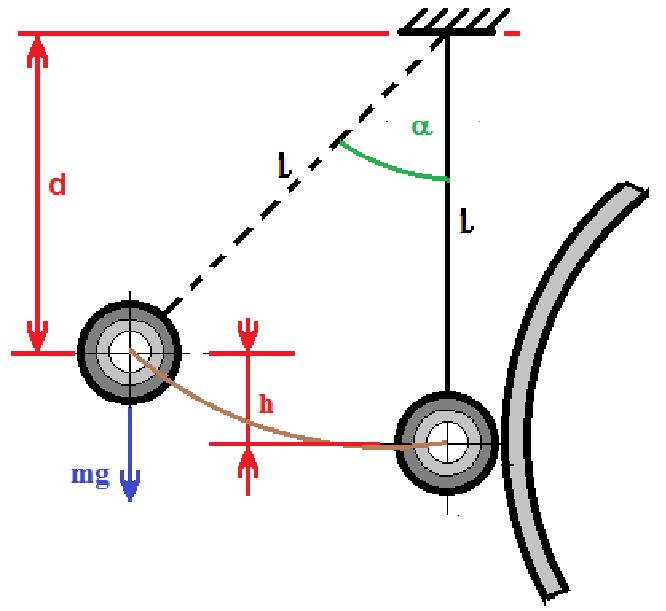

Fig. 4. Sheme of the ball and piston ring collision 
To the calculation of the energy:

$$
k=\frac{2}{3\left(1-\mu_{1}\right)\left(1+\mu_{2}\right)} E \sqrt{\frac{r R}{r+R}} .
$$

The experiments in the determination of the spectrum-energy properties of the damped selfoscillations in the piston ring are realized with an exciting electromagnet in off condition and with operating magneto-electric sensors 4 and 5. The principle of the excitation of damped self-oscillations in the case of a single exciting hit is represented in Fig. 4. At the declination of the ball for 10 degrees the calculated time of collision $\tau$ is $0.022 \mathrm{~ms}$. For the determination of the oscillations parameters there are attempts to apply vibro-accelerometers АП-39 with symmetric magnetic suckers. The mass of all this equipment is $0.072 \mathrm{~kg}$ that distorts the result. Therefore, at this step the application of the accelerometers is excluded. For the improvement of the measurements accuracy the experiments of the investigations of mechanical self-oscillations were repeated 18-22 times.

The dependence of the duration $\tau$ (contact) of the ball collision with the ring on the angle of the ball declination is presented in Fig. 5 .

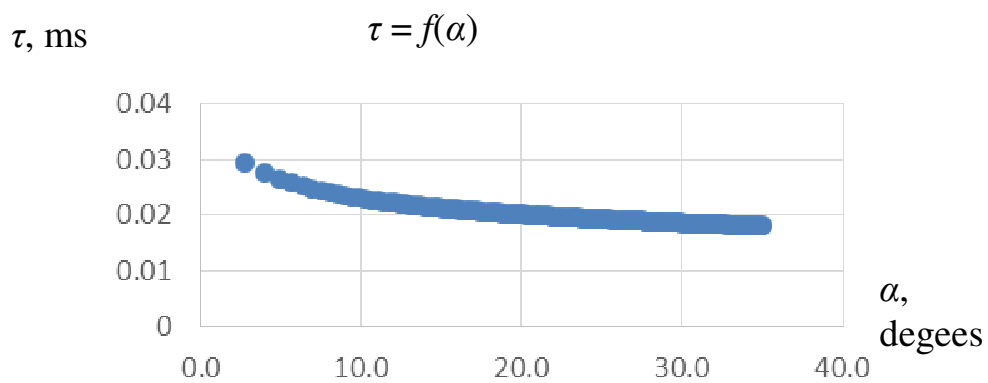

Fig. 5. Dependence of the ball collision duration on the angle

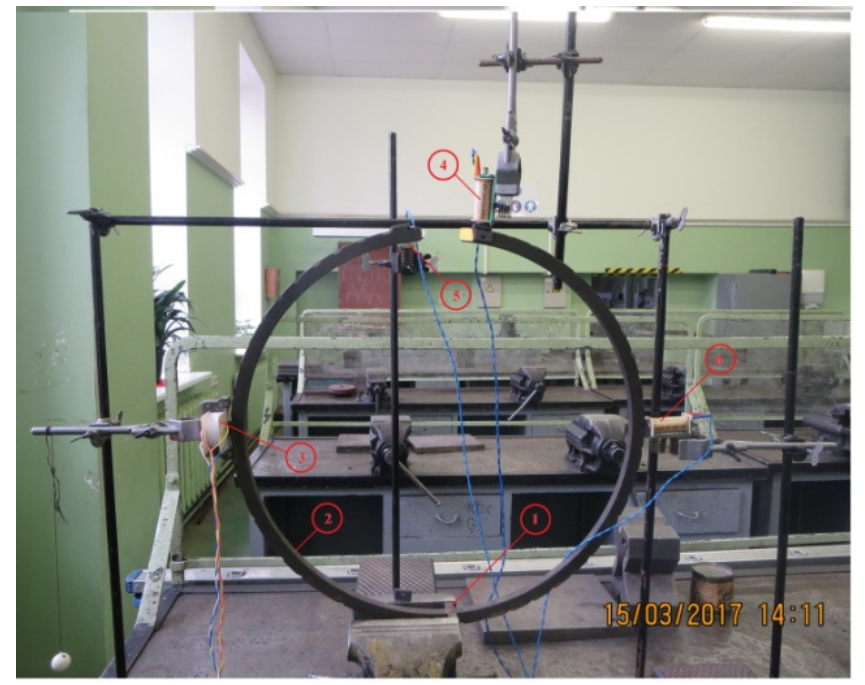

Fig. 6. Experimental board for obtaining the characteristics of the piston ring: numbering of the elements meets that of Fig. 3 of its declination

Fig. 6 presents the picture of the experimental board for obtaining of the frequency response plot of the piston ring. Fig. 7 shows the frequency response of the piston ring oscillations in the radial direction (along axis $X_{1}$, Fig. 1). The obtained result is close to those obtained in MatLab.

Fig. 8, in its turn, shows the frequency response of the oscillations of the piston ring in the direction of axis (along axis $X_{3}$, Fig. 1).

Fig. 9 presents the frequency response of the oscillations of the piston ring in the radial direction (along axis $X_{1}$ - the red colour curve - sensor 4 in Fig. 3 ) and in the direction of the axis (along $X_{3}$, the blue colour curve - sensor 5 in Fig. 3). 
HAMEG Instruments FFT CH I

DC-Ievel : $-0,001 \mathrm{~V}$ Windowf unction: Hanning -- treldiena, 2017. gada 3. maijs

$10: 54: 41$

$0,005 \mathrm{~V}$

$0.004 \mathrm{~V}$

$0.002 \mathrm{~V}$

$0,001 \mathrm{~V}$

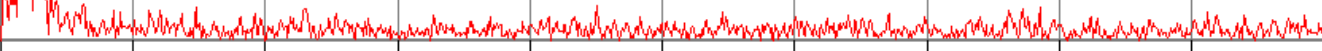

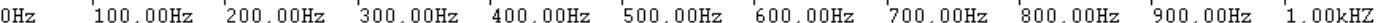

Fig. 7. Frequency response of oscillations of the piston ring in radial direction

HAMEG Instruments FFT $\mathrm{CH}$ II

DC-Level : $-0,014 \mathrm{~V}$ Windowf unction: Welch -- treldiena, 2017. gada 3. maijs 11:24:56

$0.068 \mathrm{~V}$

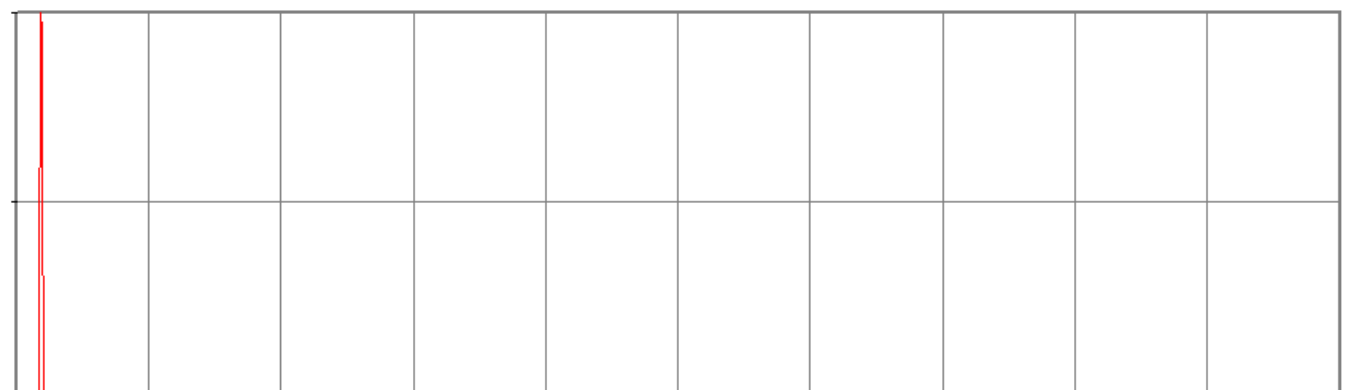

$0,041 \mathrm{~V}$

$0.027 \mathrm{~V}$

$0.014 \mathrm{~V}$

$0,000 \mathrm{~V}$

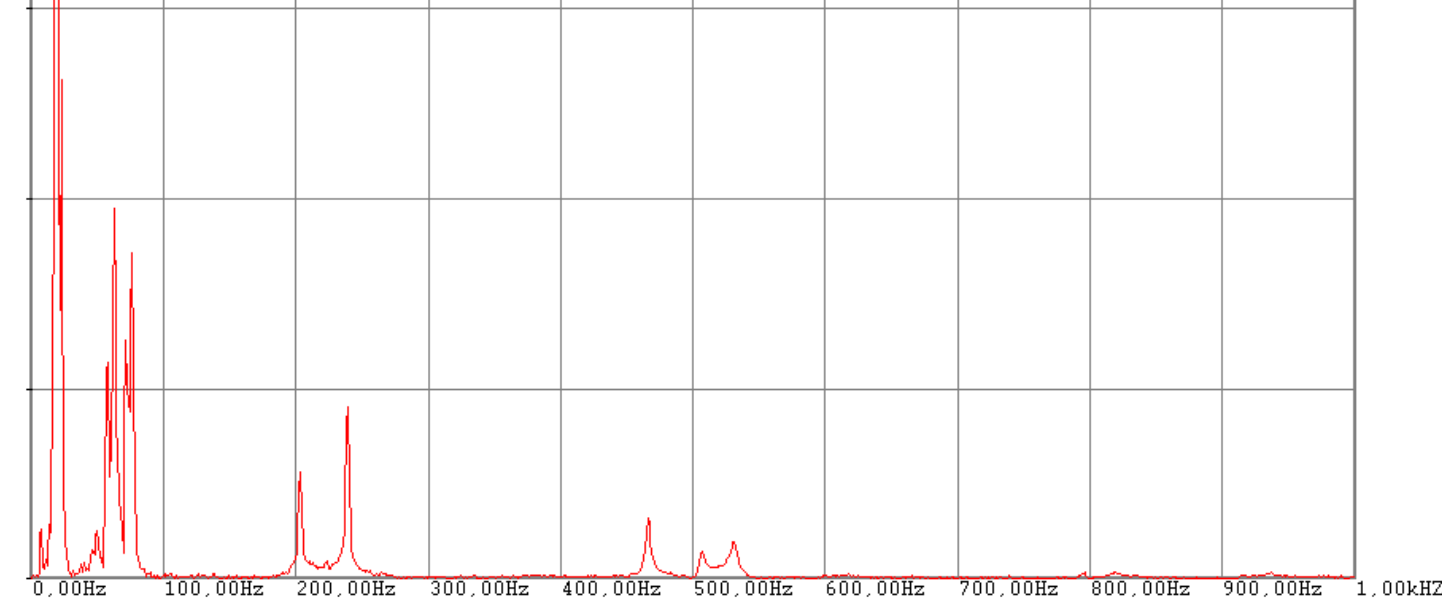

Fig. 8. Frequency response of oscillations of the piston ring in the direction of axis 


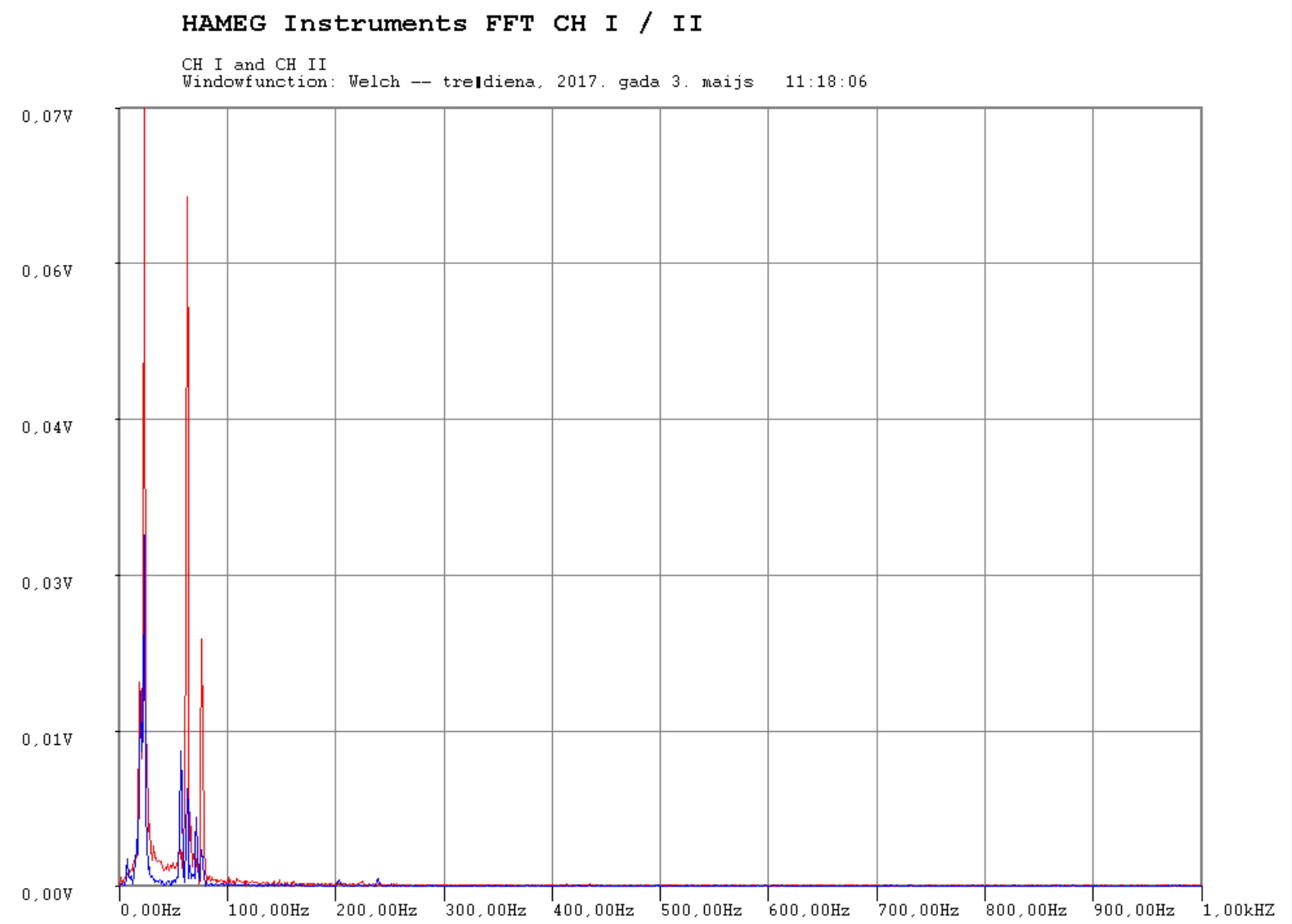

Fig. 9. Frequency response of oscillations of the piston ring in the radial direction (along axis $X_{1}$ ) and in the direction of axis (along axis $X_{3}$ )

Further, the obtained measured information was processed by means of software MatLAB. As an example Fig. 7-9 represent the spectral components of the self-oscillations of a defect-free piston ring. The basic frequency of its oscillations is $18 \ldots .21 \mathrm{~Hz}$, the duration of the process $-18-20 \mathrm{~s}$. Theoretically calculated frequency could differ from a real value. The reason of the differences could be the assumed rectangular form of the ring`s cross-section, as the real ring has uniformly distributed inclined grooves for oil removing that were not taken into account at the calculations. But that is the question to be considered in another particular paper. Grooves of oil removing of the piston ring shown in Fig. 10.

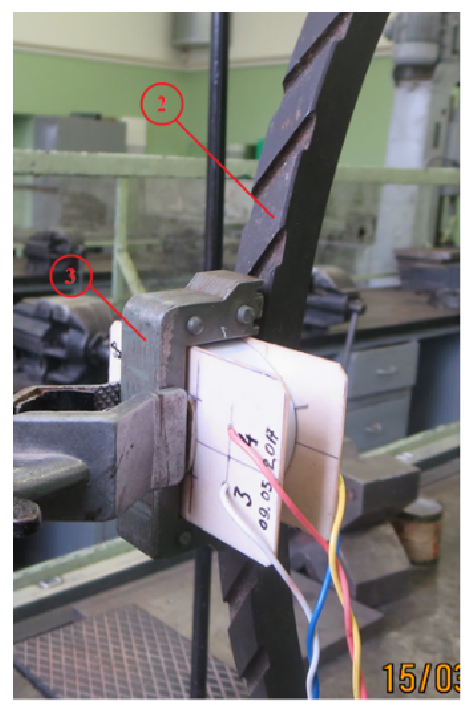

Fig. 10. Grooves of oil removing of the piston ring 
At the initial (unmovable) condition the gap between the iron core of the sensors 4 and 5 (Fig. 3) is $0.4 \mathrm{~mm}$. Maximum amplitude of the ring's oscillations is $0.3 \mathrm{~mm}(0.15 \mathrm{~mm}$ for side). The highest harmonic components of the oscillations achieve about $550 \mathrm{~Hz}$. The characteristics of the frequency response of the pistons ring oscillations were taken simultaneously in the radial and axis directions (Fig. 9) at both sides $\mathrm{CH} 1$ and $\mathrm{CH} 2$ of the digital oscilloscope. The self oscillations of the ring are damping exponentially.

\section{Results and discussion}

1. The described method of the control of the mechanical properties of the piston ring material can be applied at the input control of the rings. In most of the cases the conventional methods measure the geometry of the rings in close and free condition, mass of the ring, gaps.

2. Applying the method of frequency response plot analysis, the presence of micro cracks, inhomogeneity, zones with different level of thermal processing and tension can be discovered.

3. The method of this research does not require application of complex equipment.

\section{Conclusions}

1. The proposed method relates to the non-destructive methods of control.

2. Unlike the well-known methods, the FRP measurement of the ring is made simultaneously along two coordinates - along the surface of the ring, the radial oscillations, and in the axial direction perpendicular to the plane of the ring.

3. This method of the mechanical properties determination can be applied for the control of the bodies of different forms - springs, leaf springs, shafts, cylindrical casings, etc.

\section{References}

1. Biderman I.L. Theory of mechanical oscillations. -M.: Vischaja shkola, 1980. 408 p. (in Russian).

2. Graham Kelly S. Fundamentals of Mechanical Vibrations. Paperback - International Edition, June, 1993. 877 pp.

3. Tarasov S.V. The time devices. Handbook for the technical colleges in speciality (Production of time devices). M.: "Mashinostrojenije". 1976. 376 p. (in Russian).

4. Li R., Batra R. C. Buckling of axially compressed thin cylindrical shells with functionally graded middle layer. Thin-Walled Structures, vol. 44, no. 10, 2007, 1039-1047 pp.

5. Naeem M.N., Kanwal S. Vibration Characteristics of Ring-Stiffened Functionally Graded Circular Cylindrical Shells. ISRN Mechanical Engineering. Volume 2012 (2012), 13 pp.

6. Loy C. T., Lam K. Y., Reddy J. N. Vibration of functionally graded cylindrical shells. International Journal of Mechanical Sciences, vol. 41, no. 3, 1999, 309-324pp.

7. Ng T. Y., Lam K. Y., Liew K. M., Reddy J. N. Vibration of functionally graded cylindrical shells under periodic axial loading. International Journal of Computational Engineering Science, vol. 38, 2001, 1295-1309 pp.

8. Benachour A., Tahar H. D., Atmane H., A.Tounsi., A., Ahmed M. S. A four variable refined plate theory for free vibrations of functionally graded plates with arbitrary gradient. Composites Part B, vol. 42, no. 6, 2011, 1386-1394pp.

9. Benyoucef S., Mechab I., Tounsi A., Fekrar A., Adda Bedia E. A. Bending of thick functionally graded plates resting on Winkler-Pasternak elastic foundations. Mechanics of Composite Materials, vol. 46, no. 4, 2010, 425-434pp.

10. Chidamparam P., Leissa A. W. Vibrations of Planar Curved Beams, Rings, and Arches. ASME the American Society of Mechanical Engineering. Appl. Mech. Rev 46(9), 2009,467-483pp.

11. Naeem M. N., Arshad S. H., Sharma C. B. The Ritz formulation applied to the study of the vibration frequency characteristics of functionally graded circular cylindrical shells. Proceedings of the Institution of Mechanical Engineers Part C, vol. 224, no. 1, 2010, 43-54 pp.

12. Ivashencev G.I. Incresing of the service life of the piston rings by means of improvement of their vibration dampness. Summary of the doctoral thesis. Saratov Technical University. Saratov, 1997. 10 p. (in Russian).

13. Derzhansky V.B., Taratorkin I.A., Burakov I.A. Investigation of mechanics and prognosis of the destruction of the elements of the perspective hydro mechanical transmissions of the transport machines. Mashinostroenije, № 11,2007. pp. 15-23. (in Russian).

14. Motkov A.G. Automation of the defects detection of the bearing rings by means of vibro-acoustic method pulse impact. Saratov State University. 2014. 135 p. (in Russian). 